\title{
Potential role of cinnamaldehyde and costunolide to counteract metabolic syndrome induced by excessive fructose consumption
}

\author{
Ayat S. Rashwan *D, Marwa A. El-Beltagy, Sherif Y. Saleh and Ibrahim A. Ibrahim*
}

\begin{abstract}
Background: One of the serious public health problems in the world is metabolic syndrome. It includes visceral obesity, dyslipidemia, insulin resistance, hyperglycemia, and hypertension. As a contributor to almost all the classic signs of metabolic syndrome, fructose was the ideal choice. There are certain shortcomings with existing drugs for insulin-resistant treatment. Plants still represent the main source of most available medicines. Cinnamaldehyde (CNA) is an active principle of Cinnamomum zeylanicum. Costunolide (CE) is natural sesquiterpene lactones, which is the main bioactive constituent of Saussurea lappa. The main aim of the present study is to investigate the effect of the synthetic antidiabetic agent (metformin) in comparison with natural constituents (cinnamaldehyde, costunolide) after developing a reliable model for insulin resistance by using high fructose diet (HFD).

Results: It was found that HFD increased plasma glucose, insulin, glycosylated hemoglobin, HbA1c, serum total cholesterol, LDL-cholesterol, triglyceride, ALT, AST, creatinine, and uric acid. Moreover, HFD decreased hepatic reduced glutathione and superoxide dismutase levels. While oral administration of cinnamaldehyde and costunolide significantly decreased plasma glucose, $\mathrm{HbA1c}$, total cholesterol, LDL-cholesterol, triglyceride, and increased level of hepatic reduced glutathione and superoxide dismutase activity. Also, cinnamaldehyde and costunolide restored the altered plasma levels of ALT, AST, creatinine, and uric acid to normal.
\end{abstract}

Conclusions: The results of this experimental study showed that cinnamaldehyde and costunolide could be used as safe drugs for treating different abnormalities of metabolic syndrome.

Keywords: Metabolic syndrome, Fructose, Cinnamaldehyde, Costunolide, Insulin resistance

\section{Background}

The incidence of metabolic syndrome has risen worldwide mostly because of the extreme consumption of energy-dense foods and reduced physical activity. It elevates the risk of developing many serious diseases as type 2 diabetes mellitus (T2DM), cardiovascular diseases (CVD), cancer, nonalcoholic fatty liver disease (NAFLD), infertility, dementia, and other diseases [2].

Fructose is a simple sugar, a monosaccharide found in abundance in added dietary sugars, fruit, and honey [27,

\footnotetext{
* Correspondence: ayatsamy74@yahoo.com; ayatsamy44@yahoo.com Department of Biochemistry, Faculty of Vet. Medicine, Suez Canal University, Ismailia, Egypt
}

(c) The Author(s). 2019 Open Access This article is distributed under the terms of the Creative Commons Attribution 4.0 International License (http://creativecommons.org/licenses/by/4.0/), which permits unrestricted use, distribution, and reproduction in any medium, provided you give appropriate credit to the original author(s) and the source, provide a link to the Creative Commons license, and indicate if changes were made.
28]. It has a unique metabolism that leads to an increase in lipogenesis and oxidative stress [3]. Consumption of fructose for the long term is accompanied by diabetes in addition to insulin resistance and metabolic syndrome in human in addition to experimental animals [6]. The rats fed fructose 6 weeks provide an ideal model for insulin resistance study [34].

Metformin, one of biguanide glucose-lowering drugs, is considered the first medicine prescribed orally for people with T2DM [15]. In spite of using metformin for numerous years, it has only recently been valued as an insulin sensitizer [21].

Transcinnamaldehyde, an essential oil in cinnamon bark, is the cause of the prominent smell and taste of

\section{SpringerOpen}


cinnamon [10]. Cinnamaldehyde represents $98 \%$ of the components of cinnamon oil [62]. Cinnamaldehyde has several biological activities such as hypoglycemic, antihyperlipidemic, and anticancer activities $[51,56]$.

Costunolide is a well-known sesquiterpene lactone that is considered as important herbal treatment, with anti-inflammatory, anti-fungal, anti-viral properties, antipyretic, anti-ulcer, and antimycobacterial activities [46]. In addition to the powerful ability of costunolide to decline serum total cholesterol (TC), LDL-cholesterol and triglyceride (TG), it also elevates plasma insulin, tissue glycogen, serum protein, and HDL-cholesterol [55].

The objective of the current study was the comparison of the effect of cinnamaldehyde and costunolide on a model of insulin resistance induced by the consumption of high fructose diet.

\section{Methods}

\subsection{Experimental animals}

The current study was carried out on a total number of 40 healthy male albino rats; weighing $220-290 \mathrm{~g}$. They were housed in metal cages in an air-conditioned room maintained at $22 \pm 2{ }^{\circ} \mathrm{C}$ with a 12 -h light/12-h dark cycle and allowed free access to food and water. They were maintained on a standard balanced ration for 2 weeks accommodation (Table 1) according to [40].

\subsection{Drugs and chemicals}

- Fructose was purchased as white crystals (Safety Misr, Specialized Food Industry Co., Cairo, Egypt).

- Cinnamaldehyde was obtained as a light yellow color liquid from Sigma-Aldrich (St. Louis, Missouri, USA).

- Costunolide was supplied as a white powder from Herbest (Baoji Herbest Bio-Tech Co., Ltd).

- Metformin $\mathrm{HCl}$ (Cidophage) was supplied as tablets from CID Company, Cairo, Egypt.

- Dimethyl sulfoxide (DMSO) was purchased from s d fine-chem limited (SDFCL), Mumbai-30, India.

Table 1 Composition of standard balanced ration ( $\mathrm{g} / \mathrm{Kg}$ diet)

\begin{tabular}{ll}
\hline Ingredients & Amounts $(\mathrm{g})$ \\
\hline Poultry meal & 300 \\
Yellow corn & 480 \\
Sucrose & 50 \\
Fine wheat bran & 90 \\
Linseed oil & 40 \\
Premix & 37 \\
Methionine & 2 \\
Choline & 1 \\
\hline
\end{tabular}

\subsection{Induction of insulin resistance}

Insulin resistance was triggered by consumption of $60 \%$ fructose mixed with standard rat chow for 10 weeks. The selected percentage of fructose was based on previous study for inducing insulin resistance in rats described by [34].

\subsection{Experimental design and treatment}

Experimental animals were divided randomly into 5 groups (each group contains 8 rats) as the following.

Group I: Normal control rats that received standard rat ration all over the experiment without treatment.

Group II: Received HFD all over the experiment weeks as an insulin resistance model.

Group III: Received HFD for 10 weeks then received cinnamaldehyde at a dose $40 \mathrm{mg} / \mathrm{kg}$ described by [57] by oral gavage with HFD for 4 weeks.

Group IV: Received HFD for 10 weeks then received costunolide at a dose $20 \mathrm{mg} / \mathrm{kg}$ described by (James [17]) by oral gavage with HFD for 4 weeks.

Group V: Received HFD for 10 weeks then received metformin at a dose $300 \mathrm{mg} / \mathrm{kg}$ described by [39]by oral gavage with HFD for 4 weeks .

Treatments were administered once daily for 4 weeks. The positive and negative control groups were given an equivalent volume of DMSO 25\%.

Blood samples were taken at the end of the experiment from all groups after overnight fasting from retroorbital venous plexus then serum was obtained directly by centrifugation.

After collection of blood samples, rats were euthanized by inhalant anesthetic overdose using a bell jar followed by cervical dislocation.

Cinnamaldehyde and costunolide were prepared with mixing in $25 \%$ of DMSO for oral administration to rats while metformin tablets were crushed with a pestle and mortar then dissolved in distilled water for oral administration to rats.

\subsection{Estimation of fasting blood glucose level}

Fasting blood glucose was estimated by glucose oxidase peroxidase method [52].

\subsection{Estimation of fasting blood insulin}

Insulin is estimated by using Rat Insulin ELISA Kits, Catalog Number:-MBS289124 according to [18].

\subsection{Estimation of glycosylated hemoglobin}

Fully automated auto-analyzer Cobas C311 (Roche Diagnostics, Germany) was used in glycosylated hemoglobin (HbA1c) estimation. 


\subsection{Calculation of HOMA-IR index}

Homeostasis model assessment of insulin resistance (HOMA- IR) index was calculated according to the following formula:

(Fasting blood insulin $(\mathrm{U} / \mathrm{L}) \times$ Fasting blood glucose $(\mathrm{mg} / \mathrm{dL}) / 405)$

\subsection{Estimation of lipids profile}

TC, TG, and HDL-cholesterol levels in plasma were estimated using kits Biomed Diagnostics, Badr City, Egypt. Friedewald's equation is used in LDL-cholesterol level calculation [19].

\subsection{Estimation of antioxidants}

Determination of reduced glutathione (GSH) was based on [8]. Colorimetric assay of superoxide dismutase determination was based on [42] method.

\subsection{Estimation of liver and kidney function tests}

Activities of alanine aminotransferase (ALT) and aspartate aminotransferase (AST) were determined by [7] method. The kinetic colorimetric assay of creatinine estimation is based on the [26] method. Uric acid level was estimated according to [52] method.

\subsection{Statistical analysis}

Statistical analysis was carried out by Statistical Package for the Social Sciences (SPSS version 20.0) software for analysis of data and Duncan's multiple range test for determination of LSD.

\section{Results}

\subsection{Effect of cinnamaldehyde and costunolide on body} weight

There was a significant $(p \leq 0.05)$ decrease in average body weight in the HFD-treated group when compared with normal control group. Moreover, treated groups with cinnamaldehyde, costunolide, and metformin showed no significance in average body weight when compared with HFD as illustrated in (Table 2).

Table 2 Effect of oral administration of cinnamaldehyde and costunolide on body weight in HFD fed rats for 30 days

\begin{tabular}{lll}
\hline Groups & \multicolumn{2}{l}{ Body weight $(\mathrm{gm})$} \\
\cline { 2 - 3 } & Before treatment & After treatment \\
\hline Control & $297.02^{\mathrm{a}} \pm 9.67$ & $322.00^{\mathrm{a}} \pm 9.14$ \\
HFD & $249.00^{\mathrm{b}} \pm 14.94$ & $243.30^{\mathrm{b}} \pm 13.05$ \\
HFD+ Cinnmaldehyde $(40 \mathrm{mg} / \mathrm{kg})$ & $251.70^{\mathrm{b}} \pm 15.24$ & $262.80^{\mathrm{b}} \pm 32.38$ \\
HFD+ Costunolide $(20 \mathrm{mg} / \mathrm{kg})$ & $241.98^{\mathrm{b}} \pm 15.25$ & $242.00^{\mathrm{b}} \pm 13.73$ \\
HFD+ Metformin $(300 \mathrm{mg} / \mathrm{kg})$ & $245.90^{\mathrm{b}} \pm 10.69$ & $239.90^{\mathrm{b}} \pm 3.71$ \\
\hline
\end{tabular}

Values are means \pm SE

Means carrying different superscripts considered significant $(P<0.05)$

\subsection{Effect of cinnamaldehyde and costunolide on fasting} blood glucose, insulin, HbA1c \%, and HOMA-IR

There was a significant increase in fasting blood glucose, insulin, HbAlc \%, and HOMA-IR in HFD treated group when compared with normal control group. Cinnamaldehyde- and costunolide-treated groups showed a significant decrease in fasting blood glucose level when compared with HFD-treated group. On the other hand, cinnamaldehydetreated group showed a significant decrease in fasting blood glucose level when compared to costunolide. Also, cinnamaldehyde treated group showed a significant increase in blood insulin level when compared with normal control group. Moreover, costunolide- and metformin-treated groups showed no difference in blood insulin level when compared with control- and HFD-treated group. Moreover, cinnamaldehyde-, costunolide-, and metformin-treated groups showed a significant decrease in HbA1c \% when compared with HFD-treated group. Furthermore, there was a significant decrease in HOMA-IR in cinnamaldehyde-, costunolide-, and metformin-treated groups when compared with HFD-treated group as illustrated in (Table 3).

\subsection{Effect of cinnamaldehyde and costunolide on lipids profile}

There was a significant increase in the levels of triacylglycerol, total cholesterol, and LDL-cholesterol in HFDtreated group when compared with normal control group. There was a significant decrease in triacylglycerol, total cholesterol, and LDL-cholesterol levels in cinnamaldehyde, costunolide, and metformin treated groups when compared with HFD-treated group. There was a significant decrease in HDL-cholesterol level in HFDtreated group when compared with normal control group. Moreover, there was a significant increase in HDL-cholesterol level in cinnamaldehyde, costunolide and metformin treated groups when compared with HFD-treated group as illustrated in (Table 4).

\subsection{Effect of cinnamaldehyde and costunolide on antioxidants}

There was a significant decrease in GSH level and SOD activity in the HFD-treated group when compared with normal control group. On the other hand, there was a significant increase in GSH level and SOD activity in cinnamaldehyde-, costunolide-, and metformin-treated groups when compared with HFD treated group as illustrated in (Table 5).

\subsection{Effect of cinnamaldehyde and costunolide on liver and kidney function tests}

There was a significant increase in ALT and AST levels in the HFD-treated group when compared with normal control group. Treatment with cinnamaldehyde, costunolide, and metformin significantly decreased ALT and 
Table 3 Effect of oral administration of cinnamaldehyde and costunolide on fasting blood glucose, insulin, HbA1c \% and HOMA-IR in HFD fed rats for 30 days

\begin{tabular}{lllll}
\hline Groups & $\begin{array}{l}\text { Glucose } \\
(\mathrm{mg} / \mathrm{dl})\end{array}$ & $\begin{array}{l}\text { Insulin } \\
\mathrm{mlU} / \mathrm{mL})\end{array}$ & HbA1c\% & HOMA-IR \\
\hline Control & $85.33^{\mathrm{c}} \pm 5.36$ & $0.98^{\mathrm{b}} \pm 0.09$ & $3.43^{\mathrm{b}} \pm 0.19$ & $0.21 \mathrm{c} \pm 0.03$ \\
HFD & $167.00^{\mathrm{a}} \pm 7.09$ & $1.66^{\mathrm{a}} \pm 0.11$ & $5.70^{\mathrm{a}} \pm 0.52$ & $0.68 \mathrm{a} \pm 0.04$ \\
HFD+ Cinnmaldehyde $(40 \mathrm{mg} / \mathrm{kg})$ & $91.00^{\mathrm{c}} \pm 3.21$ & $1.56^{\mathrm{a}} \pm 0.17$ & $3.50^{\mathrm{b}} \pm 0.10$ & $0.34 \mathrm{~b} \pm 0.03$ \\
HFD+ Costunolide $(20 \mathrm{mg} / \mathrm{kg})$ & $123.00^{\mathrm{b}} \pm 8.71$ & $1.34^{\mathrm{ab}} \pm 0.19$ & $4.23^{\mathrm{b}} \pm 0.27$ & $0.40 \mathrm{~b} \pm 0.03$ \\
HFD+ Metformin $(300 \mathrm{mg} / \mathrm{kg})$ & $111.67^{\mathrm{b}} \pm 5.54$ & $1.37^{\mathrm{ab}} \pm 0.12$ & $3.63^{\mathrm{b}} \pm 0.34$ & $0.34 \mathrm{~b} \pm 0.04$ \\
\hline
\end{tabular}

Values are means \pm SE

Means carrying different superscripts considered significant $(P<0.05)$

AST levels when compared with HFD-treated group. There was a significant increase in the levels of creatinine and uric acid in the HFD-treated group when compared with normal control group. Treatment either with cinnamaldehyde or costunolide significantly decreased creatinine and uric acid levels when compared to HFDtreated group. While there was no significant change in creatinine level between metformin, HFD treated group and control group. Oral treatment with metformin significantly decreased uric acid level as compared with HFD-treated group as illustrated in (Table 6).

\section{Discussion}

The metabolic syndrome is one of the major and growing public health and clinical challenge globally as a consequence of urbanization, surplus energy intake, and spreading of obesity. Metabolic syndrome causes an increase in the risk of incidence of T2DM and CVD to be 5-fold and 2-fold respectively [29].

In this study, it was used a high percentage of fructose $(60 \%)$ to produce metabolic syndrome in rats as the rats are likely resistant to fructose as hyperuricemia induced by fructose is hindered because of the presence of uricase enzyme. Rats also can synthesize vitamin $C$ that inhibits fructose-induced insulin resistance. Furthermore, vitamin $\mathrm{C}$ also inhibits the reaction of uric acid with various oxidants and counteracts the effect of fructose or uric acid to stimulate oxidative stress in adiposities [48].

The feeding of HFD for 14 weeks leads to a decrease in body weight. On the other hand, an increase in visceral adipose tissue mass visually observed in this group during an autopsy. This result in agreement with [25]. There is more than one explanation for decreasing the body weight in HFD consumption in this study. It is interesting that rats feed on HFD may not show an increase in overall body weight if it is not associated with diets high in fat [32]. Excessive consumption of fructose is accompanied by a decrease in body weight because of excessive muscle wasting and wastage of tissue protein due to renal failure. The body weight of rats depending on HFD significantly decreased, which may be a result of fructose intolerance because of early excessive intake of fructose in the diet [25]. There was a significant increase in fasting blood glucose, HbA1c, insulin levels, and HOMA-IR in HFD group when compared with normal control group. These results are similar to those reported by [24, 34]. It has been reported that longterm high-fructose feeding causes a reduction in the glucokinase activity and an increase in glucose-6-phosphatase activity in the liver leading to enhanced gluconeogenesis from fructose [45]. Fructose consumption enhances de novo ceramide biosynthesis and elevates ceramide concentrations in the plasma, liver, and skeletal muscle that induce local insulin resistance [61]. Furthermore, there was a significant increase in triacylglycerol, total cholesterol and LDLcholesterol levels in HFD group. On the other hand, there was a significant decrease in HDL-cholesterol level.

Fructose enhances hepatic de novo lipogenesis and decreases hepatic fatty acid oxidation, both of which can lead to increased fat accumulation in the liver, which then excites inflammation and hepatic insulin resistance [13]. Moreover, fructose improves oxidative stress and mitochondrial dysfunction that resulting in peroxisome

Table 4 Effect of oral administration of cinnamaldehyde and costunolide on serum lipids levels in HFD fed rats for 30 days

\begin{tabular}{lllll}
\hline Groups & Triacylglycerol $(\mathrm{mg} / \mathrm{dl})$ & Total Cholesterol $(\mathrm{mg} / \mathrm{dl})$ & $\begin{array}{l}\mathrm{LDL}-\mathrm{c} \\
(\mathrm{mg} / \mathrm{d})\end{array}$ & $\begin{array}{l}\mathrm{HDL}-\mathrm{c} \\
(\mathrm{mg} / \mathrm{dl})\end{array}$ \\
\hline Control & & & $50.47^{\mathrm{c}} \pm 7.59$ & $52.33^{\mathrm{a}} \pm 3.52$ \\
HFD & $99.33^{\mathrm{b}} \pm 4.09$ & $122.67^{\mathrm{c}} \pm 6.69$ & $174.73^{\mathrm{a}} \pm 2.67$ & $34.00^{\mathrm{b}} \pm 2.64$ \\
HFD+ Cinnmaldehyde $(40 \mathrm{mg} / \mathrm{kg})$ & $159.66^{\mathrm{a}} \pm 11.14$ & $240.67^{\mathrm{a}} \pm 2.13$ & $78.60^{\mathrm{bc}} \pm 8.75$ & $52.67^{\mathrm{a}} \pm 2.90$ \\
HFD+ Costunolide $(20 \mathrm{mg} / \mathrm{kg})$ & $78.67^{\mathrm{b}} \pm 2.72$ & $147.00^{\mathrm{bc}} \pm 6.42$ & $92.07^{\mathrm{bc}} \pm 1.45$ & $46.00^{\mathrm{a}} \pm 7.00$ \\
HFD+ Metformin $(300 \mathrm{mg} / \mathrm{kg})$ & $101.33^{\mathrm{b}} \pm 8.09$ & $158.33^{\mathrm{b}} \pm 9.20$ & $99.67^{\mathrm{b}} \pm 4.60$ & $45.67^{\mathrm{a}} \pm 3.06$ \\
\hline
\end{tabular}

Values are means $\pm \mathrm{SE}$

Means carrying different superscripts considered significant $(P<0.05)$ 
Table 5 Effect of oral administration of cinnamaldehyde and costunolide on plasma antioxidants levels in HFD fed rats for 30 days

\begin{tabular}{lll}
\hline Groups & GSH $(\mathrm{mmo} / \mathrm{L})$ & SOD $(\mathrm{U} / \mathrm{m} /)$ \\
\hline Control & $2.25^{\mathrm{a}} \pm 0.21$ & $3.47^{\mathrm{ab}} \pm 0.25$ \\
HFD & $1.12^{\mathrm{b}} \pm 0.13$ & $1.14^{\mathrm{c}} \pm 0.09$ \\
HFD+ Cinnmaldehyde $(40 \mathrm{mg} / \mathrm{kg})$ & $2.36^{\mathrm{a}} \pm 0.20$ & $3.90^{\mathrm{a}} \pm 0.02$ \\
HFD+ Costunolide $(20 \mathrm{mg} / \mathrm{kg})$ & $2.08^{\mathrm{a}} \pm 0.06$ & $2.50^{\mathrm{b}} \pm 0.15$ \\
HFD+ Metformin (300 mg/kg) & $1.90^{\mathrm{a}} \pm 0.21$ & $2.74^{\mathrm{b}} \pm 0.63$ \\
\hline
\end{tabular}

Values are means $\pm \mathrm{SE}$

Means carrying different superscripts considered significant $(P<0.05)$

proliferator-activated receptor-gamma coactivator 1- $\alpha$ stimulation that leads to insulin resistance [27, 28].

High fructose diet feeding has resulted in an increase in fasting uric acid. The metabolism of fructose has been shown to stimulate the production of UA. As fructose 1phosphate increases intracellular, phosphate declines. This reduction stimulates AMP deaminase (AMPD) that catalyzes the catabolism of AMP to inosine monophosphate, raising purine degradation rate. Degradation of purine generates uric acid [9].

There was a significant reduction in GSH level and SOD activity in the HFD treated group when compared to normal control group. During fructose metabolism, ATP exhaustion and stimulation of oxidative stress and inflammatory response occurs. Overproduction of indirect dangerous factors such as inflammatory cytokine, endotoxin, and adiponectin leads to disturbance in functions of tissues and organs [61].

In the current study, we observed a significant increase in ALT, AST, and serum creatinine levels in the HFDtreated group. These results can be explained through that most of the tissue damage is resulted by free radicals, which damage the cell membrane by unsaturated fatty acids peroxidation [38]. The predominant adverse consequences of fructose are due to its rapid uncontrolled metabolism, especially in the liver [53].

Metformin is one of the most efficient drugs for the treatment of type 2 diabetes and also acts as insulin sensitizer $[37,50]$. Our results demonstrated that metformin has no difference in average body weight with HFD-treated group, but it was observed treatment with metformin decrease the average body weight when compared with before metformin treatment. Treatment with metformin has been exhibited an anorectic effect in rodents and humans [35].

In the current study, the metformin-treated group showed a decrease in fasting blood glucose, HOMA-IR, and HbA1c when compared with HFD-treated group. Metformin mainly reduces production of hepatic glucose by a slight suppression of the mitochondrial respiratorychain complex1. As a consequence, the transient reduction in cellular energy status enhances activation of AMPK that stimulates glucose uptake in muscle and liver, glycolysis, fatty acid oxidation, and suppresses of glycogen, fatty acid and cholesterol synthesis, and gluconeogenesis $[11,54]$. Metformin-treated group showed no difference in blood insulin levels when compared with normal control and HFD-treated group. This finding may be due to that metformin slightly increases secretion of insulin with enhancement of insulin sensitivity [59].

Metformin treatment showed a significant reduction in triacylglycerol, total cholesterol, and LDL-cholesterol levels when compared with HFD-treated group. On the other hand, there was a significant enhancement in HDLcholesterol level as compared with HFD. The enhancement that occurs in lipid profile by metformin has resulted from activation of AMPK in hepatic cells; as a result, acetyl-CoA carboxylase (ACC) activity is decreased.

At present, there was a significant increase in GSH level and SOD activity in metformin-treated group when compared with HFD. Metformin has an antioxidative effect as it inhibits cytokine-induced $N_{F} B$ activation through activation of AMPK pathway [36, 47]. Metformin also exerts its antioxidant activity via enhancing the activity of antioxidant enzymes, reducing the lipid peroxidation markers, and suppressing AGEs formation which promotes inflammation and ROS (glycoxidation) [31].

The current study demonstrated a significant decrease in the serum level of ALT, AST, and uric acid but no significance in creatinine levels between metformin and HFD-treated group. Metformin decreases gluconeogenesis that may explain the decrease in liver enzymes [58].

Table 6 Effect of oral administration of cinnamaldehyde and costunolide on liver and kidney function tests in HFD fed rats for 30 days

\begin{tabular}{lllll}
\hline Groups & ALT $(U / L)$ & AST $(U / L)$ & Creatinine $(\mathrm{mg} / \mathrm{dl})$ & Uric acid $(\mathrm{mg} / \mathrm{dl})$ \\
\hline Control & $37.33^{\mathrm{b}} \pm 3.76$ & $17.33^{\mathrm{bc}} \pm 3.17$ & $0.87^{\mathrm{bc}} \pm 0.06$ & $4.20^{\mathrm{c}} \pm 0.38$ \\
HFD & $57.00^{\mathrm{a}} \pm 5.50$ & $43.33^{\mathrm{a}} \pm 3.48$ & $1.23^{\mathrm{a}} \pm 0.42$ & $7.59^{\mathrm{a}} \pm 0.31$ \\
HFD+ Cinnmaldehyde $(40 \mathrm{mg} / \mathrm{kg})$ & $24.33^{\mathrm{b}} \pm 1.76$ & $16.33^{\mathrm{c}} \pm 1.20$ & $0.77^{\mathrm{c}} \pm 0.43$ & $5.74^{\mathrm{b}} \pm 0.07$ \\
HFD+ Costunolide $(20 \mathrm{mg} / \mathrm{kg})$ & $33.33^{\mathrm{b}} \pm 8.09$ & $27.33^{\mathrm{b}} \pm 2.33$ & $0.82^{\mathrm{bc}} \pm 0.49$ & $6.05^{\mathrm{b}} \pm 0.19$ \\
HFD+ Metformin $(300 \mathrm{mg} / \mathrm{kg})$ & $32.33^{\mathrm{b}} \pm 4.91$ & $21.33^{\mathrm{bc}} \pm 4.33$ & $1.14^{\mathrm{ab}} \pm 0.57$ & $6.07^{\mathrm{b}} \pm 0.22$ \\
\hline
\end{tabular}

Values are means $\pm \mathrm{SE}$

Means carrying different superscripts considered significant $(P<0.05)$ 
The ability of metformin to decrease the serum level of uric acid is depending on activation of AMPK signaling pathway [23]. Lactic acidosis associated with metformin occurs in the case of an inability to properly excrete it, as in kidney injury caused by a high fructose diet, because metformin is cleared from blood mainly via the renal route. Lactic acidosis decreases renal functions; in these case, metformin did not improve the function of kidney [12].

It was found in this study that there was no significance in average body weight in cinnamaldehyde treated group when compared with HFD group, but it was clear that cinnamaldehyde treatment increase body weight when compared with body weight before treatment. This finding result may be due to cinnamon bark enhancing appetite, and it also has the ability to relief of gastric distress [43].

Treatment with cinnamaldehyde reduced fasting blood glucose, HbA1c, and HOMA-IR when compared with HFD-treated group. Cinnamaldehyde showed an increase in serum insulin level and when this increase compared with HFD-treated group showed no difference. These results associated with cinnamaldehyde raise pyruvate kinase level and decline phosphoenolpyruvate carboxykinase level in hepatic tissues, two key enzymes included in homeostasis of glucose. The treatment with cinnamaldehyde showed a marked increase in plasma insulin that leads to a reduction in ATP, a known allosteric inhibitor of Pyruvate kinase (PK), thereby increasing the activity of PK to near normal and stimulate glycolysis. Also, cinnamaldehyde reversed the increase of hepatic phosphoenolpyruvate carboxykinase enzyme (PEPCK) levels and by that reduce hepatic gluconeogenesis. Cinnamaldehyde was detected to enhance the glucose uptake in peripheral tissues. It was found that cinnamaldehyde acts by stimulating the release of insulin via $\beta$-cells of pancreas [4].

A treated group with cinnamaldehyde showed a significant improvement in lipid profile as it enhances lipolysis in adipose tissue [30].

It was noticed that cinnamaldehyde treatment significantly increase GSH level and SOD activity when compared with HFD-treated group as it enhanced the antioxidant defense of reactive oxygen species produced in hyperglycemia [22].

The present study demonstrated cinnamaldehyde restored liver enzymes levels to normal as it exhibited a protective effect on liver. It was recorded in previous studies that cinnamon extract has increased the levels of serum total protein towards the respective normal value, which indicates hepatoprotective activity. Stimulation of protein synthesis has been advanced as a contributory hepatoprotective mechanism which accelerates the regeneration process and the production of liver cells and that explain the powerful effect of cinnamaldehyde to restore liver enzymes to normal levels [14]. It also decreased inflammation and steatosis in hepatic tissues of rats reflecting the hepatoprotective effect of CNA against degeneration $[1,49]$. A previous study also explained the hepatoprotective effect of cinnamon by preventing oxidative damage caused by fatty acids in liver tissue through rebalancing antioxidant enzymes which by the way eliminates cellular damage and that reflected on the enzymatic function of this organ [41]. Also, it was found cinnamaldehyde treatment improves kidney function as cinnamaldehyde inhibited nephropathy caused by (AGE) products through suppression of the NO pathway activated by the JAK2-STAT1/STAT3 pathway [22]. Furthermore, it significantly improves oxidative stress in renal tissues by suppression of free radical generation and potentiation of ADS elements [60]. Also, oral administration of cinnamaldehyde decreases serum uric acid levels and that can be explained by its ability to inhibit the activity of xanthine oxidase enzyme [33].

It was found in this study that costunolide showed a significant reduction in the blood glucose level, $\mathrm{HbA1c}$, and HOMA-IR when compared with HFD-treated group. While it showed no significant difference in serum insulin levels when compared with HFD-treated group and control group. The reduction in blood glucose level indicated that costunolide might have an insulin-like effect on peripheral tissues by enhancing glucose uptake and suppressing hepatic gluconeogenesis [17]. Costus plant is known as insulin plant [5]. It was found that there is an increase in insulin level in diabetic rats treated with Costus pictus leaf extract and that resulted from stimulation of the intact $\beta$ cells of pancreas [20]. The ability of costunolide to stimulate $\beta$ cells of pancreas to secrete insulin may be due to suppress the production of NO [44].

There was a significant increase in GSH level and SOD activity in costunolide-treated group when compared with HFD-treated group. Also, it was noticed in this study that oral administration of costunolide significantly decreased the AST, ALT, serum creatinine, and uric acid levels. Costunolide restores the normal concentration of GSH that may enhance mechanisms of the cellular defense, suppress lipid peroxidation, and consequently protect the body tissues against oxidative damage. These results showed the effective mechanism of costunolide by lowering the oxidative damage and increasing the cellular antioxidant pool [16].

\section{Conclusion}

Finally, our results showed that cinnamaldehyde and costunolide are considered as potential antidiabetic and antioxidant agents. Metformin is contraindicated to use in case of renal impairment. According to our present study, cinnamaldehyde and costunolide could be considered as an additional dietary supplements option to prevent and regulate underlying complications along with conventional medications to treat insulin resistance. 
Many unanswered questions remain regarding costunolide, so there is a need for more studies on the molecular level and different doses of costunolide.

\begin{abstract}
Abbreviations
ACC: Acetyl-CoA carboxylase; AGEs: Advanced glycation end products; ALT: Alanine aminotransferase; AMP: Adenosine monophosphate; AMPD: Adenosine monophosphate deaminase; AMPK: 5' adenosine monophosphate-activated protein kinase; AST: Aspartate aminotransferase; CE: Costunolide; CNA: Cinnamaldehyde; CVD: Cardiovascular disease; DMSO: Dimethyl sulfoxide; GSH: Reduced glutathione; HbA1c: Glycosylated hemoglobin; HDL-cholesterol: High-density lipoprotein cholesterol; HFD: High fructose diet; HOMA-IR: Homeostasis model assessment of insulin resistance; JAK2-STAT1/STAT3: Janus kinase 2/signal transducer and activator of transcription1/3; LDL-cholesterol: Low-density lipoprotein cholesterol; NAFLD: Nonalcoholic fatty liver disease; NFKB: Nuclear factor kappa-lightchain-enhancer of activated B cells; NO: Nitric oxide;

PEPCK: Phosphoenolpyruvate carboxykinase; PK: Pyruvate kinase; ROS: Reactive oxygen species; SOD: Superoxide dismutase; SPSS: Statistical Package for the Social Sciences; T2DM: Type 2 diabetes mellitus; TC: Total cholesterol; TG: Triglyceride
\end{abstract}

\section{Acknowledgements}

My heartfelt thanks and gratitude to Prof. Dr. Walid F. Khalil, Professor of Pharmacology, Faculty of Veterinary Medicine, Suez Canal University for its help in this study.

\section{Authors' contributions}

AR participated in the design of the study and carried out the biochemical examination. ME participated in the design of the study and performed the statistical analysis. SS participated in the design of the study and in the sequence alignment and drafted the manuscript. II conceived of the study and participated in the design of the study and in the sequence alignment and drafted the manuscript. All authors have read and approved the manuscript.

\section{Funding}

This research did not receive any specific grant from funding agencies in the public, commercial, or not-for-profit sectors.

\section{Availability of data and materials}

Not applicable.

\section{Ethics approval and consent to participate}

Ethical approval for this study was obtained from ethics of scientific research committee, Faculty of Veterinary Medicine, Suez Canal University, Ismailia, Egypt (No.201601).

\section{Consent for publication}

Not applicable

\section{Competing interests}

The authors declare that they have no competing interests.

Received: 1 July 2019 Accepted: 15 November 2019

Published online: 09 December 2019

\section{References}

1. Abdelmageed ME, Shehatou GS, Abdelsalam RA, Suddek GM, Salem HA (2018) Cinnamaldehyde ameliorates STZ-induced rat diabetes through modulation of IRS1/PI3K/AKT2 pathway and AGEs/RAGE interaction. Naunyn-Schmiedeberg's Archives of Pharmacology. https://doi.org/10.1007/s00210-018-1583-4

2. Ahima RS (2016) Metabolic syndrome a comprehensive textbook

3. Ahmed MA, Ali NA, Elbast SAA, Mohamed* MA (2018) Rice bran oil ameliorates hepatic insulin resistance in fructose fed-rats. The Egyptian Journal of Hospital Medicine 71:2885-2891

4. Anand P, Murali KY, Tandon V, Murthy PS, Chandra R (2010) Insulinotropic effect of cinnamaldehyde on transcriptional regulation of pyruvate kinase, phosphoenolpyruvate carboxykinase, and GLUT4 translocation in experimental diabetic rats. Chemico-Biological Interactions 186:72-81. https://doi.org/10.1016/j.cbi.2010.03.044
5. Ashwini S, Bobby Z, Sridhar M, Cleetus C (2017) Insulin Plant (Costus pictus) extract restores thyroid hormone levels in experimental hypothyroidism. Pharmacognosy Research 9:51. https://doi.org/10.4103/0974-8490.199766

6. Bagul PK, Middela H, Matapally S, Padiya R, Bastia T, Madhusudana K, Reddy BR, Chakravarty S, Banerjee SK (2012) Attenuation of insulin resistance, metabolic syndrome and hepatic oxidative stress by resveratrol in fructosefed rats. Pharmacological Research 66:260-268. https://doi.org/10.1016/j. phrs.2012.05.003

7. Berger S, Tietz NW (eds) (1976) Fundamentals of clinical chemistry, 2d. Saunders, Philadelphia

8. Beutler E, Duron O, Kelly BM (1963) Improved method for the determination of blood glutathione. J. Lab. Clin. Med. 61:882-888

9. Caliceti C, Calabria D, Roda A, Cicero A (2017) Fructose intake, serum uric acid, and cardiometabolic disorders: a critical review. Nutrients 9:395. https://doi.org/10.3390/nu9040395

10. Chen Y-F, Wang Y-W, Huang W-S, Lee M-M, Wood WG, Leung Y-M, Tsai H-Y (2016) Trans-cinnamaldehyde, an essential oil in cinnamon powder, ameliorates cerebral ischemia-induced brain injury via inhibition of neuroinflammation through attenuation of iNOS, COX-2 expression and NFk-B signaling pathway. NeuroMolecular Medicine 18:322-333. https:/doi. org/10.1007/s12017-016-8395-9

11. Correia S, Carvalho C, Santos M, Seica R, Oliveira C, Moreira P (2008) Mechanisms of action of metformin in type 2 diabetes and associated complications: an overview. Mini-Reviews in Medicinal Chemistry 8:13431354. https://doi.org/10.2174/138955708786369546

12. Dichtwald S, Weinbroum AA, Sorkine P, Ekstein MP, Dahan E (2012) Metformin-associated lactic acidosis following acute kidney injury. Efficacious treatment with continuous renal replacement therapy. Diabetic Medicine 29:245-250. https://doi.org/10.1111/j.1464-5491.2011.03474.x

13. DiNicolantonio JJ, O'Keefe JH, Lucan SC (2015) Added fructose. Mayo Clinic Proceedings 90:372-381. https://doi.org/10.1016/j.mayocp.2014.12.019

14. Eidi A, Mortazavi P, Bazargan M, Zaringhalam J (2012) Hepatoprotective activity of cinnamon ethanolic extract against CCL4-induced liver injury in rats. EXCLI Journal 13

15. El Messaoudi S, Rongen GA, Riksen NP (2013) Metformin therapy in diabetes: the role of cardioprotection. Current Atherosclerosis Reports 15. https://doi.org/10.1007/s1 1883-013-0314-z

16. Eliza J, Daisy P, Ignacimuthu S (2010) Antioxidant activity of costunolide and eremanthin isolated from Costus speciosus (Koen ex. Retz) Sm. ChemicoBiological Interactions 188:467-472. https://doi.org/10.1016/j.cbi.2010.08.002

17. Eliza J, Daisy P, Ignacimuthu S, Duraipandiyan V (2009) Normo-glycemic and hypolipidemic effect of costunolide isolated from Costus speciosus (Koen ex. Retz.SSm. in streptozotocin-induced diabetic rats. Chemico-Biological Interactions 179:329-334. https://doi.org/10.1016/..cbi.2008.10.017

18. Findlay JWA, Dillard RF (2007) Appropriate calibration curve fitting in ligand binding assays. AAPS J 9:E260-E267. https://doi.org/10.1208/aapsj0902029

19. Friedewald WT, Levy Rl, Fredrickson DS (1972) Estimation of the concentration of low-density lipoprotein cholesterol in plasma, without use of the preparative ultracentrifuge. Clinical Chemistry 18:499-502

20. Gireesh G, Thomas SK, Joseph B, Paulose CS (2009) Antihyperglycemic and insulin secretory activity of Costus pictus leaf extract in streptozotocin induced diabetic rats and in in vitro pancreatic islet culture. Journal of Ethnopharmacology 123:470-474. https://doi.org/10.1016/j.jep.2009.03.026

21. Greenfield JR, Campbell LV (2004) Insulin resistance and obesity. Clinics in Dermatology, Obesity 22:289-295. https://doi.org/10.1016/j.clindermatol. 2004.01.011

22. Guo X, Sun W, Huang L, Wu L, Hou Y, Qin L, Liu T (2017) Effect of cinnamaldehyde on glucose metabolism and vessel function. Medical Science Monitor 23:3844-3853. https://doi.org/10.12659/MSM.906027

23. Hasanvand A, Amini-Khoei H, Jahanabadi S, Mehr SE, Dehpour AR (2018) Metformin attenuates streptozotocin-induced diabetic nephropathy in rats through activation of AMPK signaling pathway. Journal of Nephropathology:7

24. Hininger-Favier I, Benaraba R, Coves S, Anderson RA, Roussel A-M (2009) Green tea extract decreases oxidative stress and improves insulin sensitivity in an animal model of insulin resistance, the fructose-fed rat. Journal of the American College of Nutrition 28:355-361. https://doi.org/10.1080/ 07315724.2009.10718097

25. Huang D-W, Chang W-C, Wu JS-B, Shih R-W, Shen S-C (2016) Gallic acid ameliorates hyperglycemia and improves hepatic carbohydrate metabolism in rats fed a high-fructose diet. Nutrition Research 36:150-160. https://doi. org/10.1016/j.nutres.2015.10.001 
26. JAFFE M (1886) Ueber den Niederschlag welchen Pikrinsaure in normalen Harn erzeugt und uber eine neue Reaction des Kreatinins. Z Physiol Chem 10:391-400

27. Johnson RJ, Sanchez-Lozada LG, Nakagawa T (2010a) The effect of fructose on renal biology and disease. Journal of the American Society of Nephrology 21:2036-2039. https://doi.org/10.1681/ASN.2010050506

28. Johnson RJ, Sanchez-Lozada LG, Nakagawa T (2010b) The effect of fructose on renal biology and disease. Journal of the American Society of Nephrology 21:2036-2039. https://doi.org/10.1681/ASN.2010050506

29. Kaur J (2014) A comprehensive review on metabolic syndrome. Cardiology Research and Practice 2014:1-21. https://doi.org/10.1155/2014/943162

30. Khare P, Jagtap S, Jain Y, Baboota RK, Mangal P, Boparai RK, Bhutani KK, Sharma SS, Premkumar LS, Kondepudi KK, Chopra K, Bishnoi M (2016) Cinnamaldehyde supplementation prevents fasting-induced hyperphagia, lipid accumulation, and inflammation in high-fat diet-fed mice. Biofactors 42:201-211. https://doi.org/10.1002/biof.1265

31. Khouri H, Collin F, Bonnefont-Rousselot D, Legrand A, Jore D, Gardes-Albert M (2004) Radical-induced oxidation of metformin. European Journal of Biochemistry 271:4745-4752. https://doi.org/10.1111/j.1432-1033.2004.04438.x

32. Kretowicz M, Johnson RJ, Ishimoto T, Nakagawa T, Manitius J (2011) The impact of fructose on renal function and blood pressure. International Journal of Nephrology 2011:1-5. https://doi.org/10.4061/2011/315879

33. Lee, Y.-S., Son, E., Kim, S.-H., Lee, Y.M., Kim, O.S., Kim, D.-S., 2017. Synergistic uric acid-lowering effects of the combination of Chrysanthemum indicum linne flower and Cinnamomum cassia (L.) J. Persl Bark Extracts. Evid Based Complement Alternat Med 2017. https://doi.org/10.1155/2017/9764843

34. Liu I-M, Tzeng T-F, Liou S-S, Lan T-W (2007) Myricetin, a naturally occurring flavonol, ameliorates insulin resistance induced by a high-fructose diet in rats. Life Sciences 81:1479-1488. https://doi.org/10.1016/j.lfs.2007.08.045

35. Lv W, Wen J, Li L, Sun R, Wang J, Xian Y, Cao C, Wang Y, Gao Y (2012) The effect of metformin on food intake and its potential role in hypothalamic regulation in obese diabetic rats. Brain Research 1444:11-19. https://doi.org/ 10.1016/j.brainres.2012.01.028

36. Ma J, Yu H, Liu J, Chen Y, Wang Q, Xiang L (2015) Metformin attenuates hyperalgesia and allodynia in rats with painful diabetic neuropathy induced by streptozotocin. European Journal of Pharmacology 764:599-606. https:// doi.org/10.1016/j.ejphar.2015.06.010

37. Madiraju AK, Erion DM, Rahimi Y, Zhang X-M, Braddock DT, Albright RA, Prigaro BJ, Wood JL, Bhanot S, MacDonald MJ, Jurczak MJ, Camporez J-P, Lee H-Y, Cline GW, Samuel VT, Kibbey RG, Shulman Gl (2014) Metformin suppresses gluconeogenesis by inhibiting mitochondrial glycerophosphate dehydrogenase. Nature 510:542-546. https://doi.org/10.1038/nature13270

38. Maritim AC, Sanders RA, Watkins JB (2003) Effects of alpha-lipoic acid on biomarkers of oxidative stress in streptozotocin-induced diabetic rats. J. Nutr. Biochem. 14:288-294

39. Meddah B, Ducroc R, El Abbes Faouzi M, Eto B, Mahraoui L, BenhaddouAndaloussi A, Martineau LC, Cherrah Y, Haddad PS (2009) Nigella sativa inhibits intestinal glucose absorption and improves glucose tolerance in rats. Journal of Ethnopharmacology 121:419-424. https://doi.org/10.1016/j.jep.2008.10.040

40. National Research Council (U.S.) (1995) Nutrient requirements of laboratory animals, 4th rev. Nutrient requirements of domestic animals. National Academy of Sciences, Washington, D.C.

41. Niknezhad F, Sayad-Fathi S, Karimzadeh A, Ghorbani-Anarkooli M, Yousefbeyk F, Nasiri E (2019) Improvement in histology, enzymatic activity, and redox state of the liver following administration of Cinnamomum zeylanicum bark oil in rats with established hepatotoxicity. Anat Cell Biol 52: 302-311. https://doi.org/10.5115/acb.18.180

42. Nishikimi M, Appaji N, Yagi K (1972) The occurrence of superoxide anion in the reaction of reduced phenazine methosulfate and molecular oxygen. Biochem. Biophys. Res. Commun. 46:849-854

43. Ogawa K, Ito M (2016) Appetite-enhancing effects of trans-cinnamaldehyde, benzylacetone and 1-phenyl-2-butanone by Inhalation. Planta Medica 82: 84-88. https://doi.org/10.1055/s-0035-1558087

44. Qi L-W, Liu E-H, Chu C, Peng Y-B, Cai H-X, Li P (2010) Anti-diabetic agents from natural products - an update from 2004 to 2009. Current Topics in Medicinal Chemistry 10:434-457. https://doi.org/10.2174/156802610790980620

45. Ramesh B, Saralakumari D (2012) Antihyperglycemic, hypolipidemic and antioxidant activities of ethanolic extract of Commiphora mukul gum resin in fructose-fed male Wistar rats. Journal of Physiology and Biochemistry 68: 573-582. https://doi.org/10.1007/s13105-012-0175-x
46. Rasul A, Parveen S, Ma T (2012) Costunolide: a novel anti-cancer sesquiterpene lactone. Bangladesh Journal of Pharmacology 7. https://doi. org/10.3329/bjp.v7i1.10066

47. Saisho Y (2015) Metformin and inflammation: its potential beyond glucoselowering effect. Endocrine, Metabolic \& Immune Disorders-Drug Targets 15: 196-205. https://doi.org/10.2174/1871530315666150316124019

48. Segal MS, Gollub E, Johnson RJ (2007) Is the fructose index more relevant with regards to cardiovascular disease than the glycemic index? European Journal of Nutrition 46:406-417. https://doi.org/10.1007/s00394-007-0680-9

49. Sharma UK, Kumar R, Ganguly R, Gupta A, Sharmaand AK, Pandey AK (2018) Cinnamaldehyde, an active component of cinnamon provides protection against food colour induced oxidative stress and hepatotoxicity in albino Wistar rats. Vegetos- An International Journal of Plant Research 31:123. https://doi.org/10.5958/2229-4473.2018.00063.0

50. Sohrevardi SM, Nosouhi F, Hossein Khalilzade S, Kafaie P, Karimi-Zarchi M, Halvaei I, Mohsenzadeh M (2016) Evaluating the effect of insulin sensitizers metformin and pioglitazone alone and in combination on women with polycystic ovary syndrome: an RCT. Int J Reprod Biomed (Yazd) 14:743-754

51. Subash Babu P, Prabuseenivasan S, Ignacimuthu S (2007)

Cinnamaldehyde-a potential antidiabetic agent. Phytomedicine 14:15-22. https://doi.org/10.1016/j.phymed.2006.11.005

52. Trinder $P$ (1969) Determination of blood glucose using an oxidase-peroxidase system with a non-carcinogenic chromogen. J. Clin. Pathol. 22:158-161

53. Villegas LR, Rivard CJ, Hunter B, You Z, Roncal C, Joy MS, Le MT (2018) Effects of fructose-containing sweeteners on fructose intestinal, hepatic, and oral bioavailability in dual-catheterized rats. PLOS ONE 13:e0207024. https:// doi.org/10.1371/journal.pone.0207024

54. Viollet B, Guigas B, Garcia NS, Leclerc J, Foretz M, Andreelli F (2012) Cellular and molecular mechanisms of metformin: an overview. Clinical Science 122: 253-270. https://doi.org/10.1042/cs20110386

55. Waisundara VY, Watawana Ml, Jayawardena N (2015) Costus speciosus and Coccinia grandis : traditional medicinal remedies for diabetes. South African Journal of Botany 98:1-5. https://doi.org/10.1016/j.sajb.2015.01.012

56. Wani KD, Kadu BS, Mansara P, Gupta P, Deore AV, Chikate RC, Poddar P, Dhole SD, Kaul-Ghanekar R (2014) Synthesis, characterization and in vitro study of biocompatible cinnamaldehyde functionalized magnetite nanoparticles (CPGF Nps) for hyperthermia and drug delivery applications in breast cancer. PLOS ONE 9:e107315. https://doi.org/10.1371/journal.pone.0107315

57. Wei Z, Yan-cheng X, Fang-jian G, Ye M, Ming-li L (n.d.) Anti-diabetic effects of cinnamaldehyde and berberine and their impacts on retinol-binding protein 4 expression in rats with type 2 diabetes mellitus. Chinese Medical Journal 6

58. Yanardag R, Ozsoy-Sacan O, Bolkent S, Orak H, Karabulut-Bulan O (2005) Protective effects of metformin treatment on the liver injury of streptozotocin-diabetic rats. Human \& Experimental Toxicology 24:129-135. https://doi.org/10.1191/0960327104ht507oa

59. Yang X, Xu Z, Zhang C, Cai Z, Zhang J (2017) Metformin, beyond an insulin sensitizer, targeting heart and pancreatic $\beta$ cells. Biochimica et Biophysica Acta (BBA) - Molecular Basis of Disease 1863:1984-1990. https://doi.org/10. 1016/j.bbadis.2016.09.019

60. Yaribeygi H, Simental-Mendía LE, Butler AE, Sahebkar A (2018) Protective effects of plant-derived natural products on renal complications. Journal of Cellular Physiology. https://doi.org/10.1002/jcp.27950

61. Zhang D-M, Jiao R-Q, Kong L-D (2017) High dietary fructose: direct or indirect dangerous factors disturbing tissue and organ functions. Nutrients 9. https://doi.org/10.3390/nu9040335

62. Zhu R, Liu H, Liu C, Wang L, Ma R, Chen B, Li L, Niu J, Fu M, Zhang D, Gao S (2017) Cinnamaldehyde in diabetes: a review of pharmacology, pharmacokinetics and safety. Pharmacological Research 122:78-89. https:// doi.org/10.1016/j.phrs.2017.05.019

\section{Publisher's Note}

Springer Nature remains neutral with regard to jurisdictional claims in published maps and institutional affiliations. 